\title{
Emergency action plans: assessment of the main elements for dam break flood maps
}

\author{
A. P. Veról ${ }^{1}$, M. G. Miguez ${ }^{2}$ \& F. C. B. Mascarenhas ${ }^{2}$ \\ ${ }^{1}$ COPPE, Federal University of Rio de Janeiro, Brazil \\ ${ }^{2}$ Polytechnic School, Federal University of Rio de Janeiro, Brazil
}

\begin{abstract}
The concerns about dam safety and the consequent need to establish regulation laws for the construction and operation of dams, with the establishment of emergency plans, began to arise only after serious accidents that happened in the past, especially in the 1960s and 1970s. A dam break is usually a catastrophic event. Improved security for the downstream valley, however, can be provided through the adoption of an integrated risk and emergency management system. The document that consolidates the plan of action in case of accidents is the Emergency Action Plan (EAP). The EAP is a formal written document, which identifies the procedures to be followed by the dam operators and principal authorities involved in an emergency situation. With this document, authorities of different levels may plan how to face an eventual disaster as best as possible, working in a coordinated manner. One of the most important pieces of information for an EAP are the flood maps, containing the water depths over the valley and their times of permanence at each affected area, besides the peak discharge arrival time and the flow velocities. This work aims to present the main technical elements for preparing a flood map, which is the basic information for an EAP. In this context the failure of Funil Dam was simulated, in the Paraíba do Sul River, Brazil. In order to accomplish this objective, a pseudo two-dimensional mathematical model called MODCEL was used, developed at the Federal University of Rio de Janeiro. A distinctive characteristic of this model refers to its ability to dynamically simulate the flood plains associated with the river. The results confirm how critical the dam break problem is and reinforce the importance of developing an EAP.
\end{abstract}

Keywords: dam safety, emergency action plan, flood maps, hydrodynamic mathematical modelling, MODCEL. 


\section{Introduction}

A dam break is usually a catastrophic event. The concerns about dam safety and the consequent needs to establish regulating laws for the construction and operation of dams, according to good engineering practices, and the establishment of emergency plans, began to arise only after some serious accidents that happened in the past, especially in the 1960s and 1970s when these kind of accidents left thousands of victims all around the world.

Several countries in the world already have some type of dam safety legislation, which provides a higher control in the construction and maintenance of their dams. In this context, the International Commission on Large Dams (ICOLD) had a great importance because of its hard support on the creation of a dam safety program worldwide. In Brazil, only in 2010 was the first dam safety law enacted. This was a very important step forward, considering that over $70 \%$ of the country's energy matrix comes from hydropower and all the investments planned for new dams in the next years.

Improved security for the downstream valley can be provided through the adoption of an integrated risk and emergency management system. The document that consolidates the plan of action in case of accidents is the Emergency Action Plan (EAP). The EAP is a formal written document, which identifies the procedures and the processes that will be followed by dam operators and public authorities in an emergency situation. It is specific to each dam, considering the individuality of each project and also the specificity of the adjacent regions. With this document, authorities of different levels may plan how to face an eventual disaster as best as possible, working in a coordinated manner.

One of the most important pieces of information for an EAP are the flood maps, containing the water depths over the valley, their times of permanence at each affected area, the peak discharge arrival time and the flow velocities. To obtain these results a study on the extent of the hypothetical dam break wave and to delimitate the possibly affected areas is needed. In this sense, mathematical models are important tools for planning and support, since they allow the simulation of dam break and the consequent wave propagation.

Historically, one-dimensional models as FLDWAV, developed by the National Weather Service (NWS) and HEC-RAS, developed by the United States Army Corp of Engineers (USACE), are the most commonly ones used for this kind of simulation. Recently, with advances in computational tools, the so called two-dimensional modelling techniques are gaining more notoriety. Special emphasis is given to the physical situation in which channels and storage areas form a network in two-dimensional horizontal space, connected by onedimensional links, case where the model is called pseudo-2D or quasi-2D. This type of modelling, capable of representing the basin in a two-dimensional way, considering the plains as susceptible to the occurrence of flows, dynamically, is a significant change in the simulation of dam break. In this work, it was used a mathematical pseudo two-dimensional model called MODCEL, developed at Federal University of Rio de Janeiro. A distinctive characteristic of this model 
refers to its ability to dynamically simulate the flood plains associated with a river.

Taking advantage of MODCEL's properties, this work aims to present the main elements to prepare a flood map, which is the principal information for an EAP. In this context, it was simulated the failure of Funil Dam, in Paraíba do Sul river, Brazil.

\section{Dam safety}

The safety of a dam may be affected by natural phenomena like floods, landslides and earthquakes, as well as natural wear caused by time. The continuous monitoring of a dam performance allows a better control over it, ensuring the detection of any non-compliance that could cause failure. An effective control of dam structures, in order to minimize the chances of accidents, must count on some kind of regulation, not only to ensure their constant evaluation by dam owners, but also to standardize procedures.

According to Mccully [1], only a few countries have an adequate legislation, covering aspects such as the safety criteria for new dams, regular inspections, repair of old dams and the development of emergency action plans aiming a safe evacuation of those located downstream.

Countries like the United States, Canada, Australia, Austria, the United Kingdom, Ireland, Finland, France, Germany, Netherlands, Italy, Norway, Portugal, Spain, Sweden, Switzerland, Slovakia, Czech Republic, Romania, Latvia, New Zealand, South Africa, China, India and Russia are some of which already have dam safety laws. In Latin America, only Argentina, Chile, Mexico and, more recently, Brazil have some kind of law concerning the dams.

After some years discussing the subject, Brazil has approved, on 20 September 2010, Law Number 12334 (Brazil [2]), which provides the establishment of a National Dam Safety Policy, the creation of the National Dam Safety Council and the National Dam Safety Information System. The law should be applied for dams that meet the following characteristics: a massive height greater than or equal to 15 meters; a reservoir volume greater than or equal to $3 \mathrm{hm}^{3}$; a reservoir containing hazardous waste; or if they have medium or high potential damage associated, in terms of economic, social, environmental, or life losses.

The establishment of an Emergency Action Plan (EAP) is also stated by the new Brazilian Law. To prepare an EAP, one needs to analyse the respective flood prediction, in order to obtain the main information to outline a strategic plan for the possible affected areas in case of accident.

\section{Mathematical modelling of dam break wave}

Several mathematical models have been developed, in the scientific community, in order to simulate the dam break phenomenon and the consequent downstream flood wave propagation. The choice among these options depends on the 
complexity of each case, the physical characteristics of the dam and the valley, and the precision required on the results.

Models that represent flow conditions may be classified in simplified, hydrological models, one-dimensional hydrodynamic models (1-D), quasi-two dimensional hydrodynamic models (quasi-2D), two-dimensional hydrodynamic models (2-D) and three-dimensional hydrodynamic models (3-D).

In a process of gradual and slow formation of a breach, reservoir hydrological models may eventually be used, but if dam break is fast or instantaneous, the water profile variation along reservoir extension will demand a hydrodynamic model (Fread [3]).

One of the first models of large acceptance by the scientific community was the NWS DAMBRK, developed by the National Weather Service (NWS), in the United States. This model can be used to analyse dam break in sub-critical or supercritical channel conditions. Saint-Venant complete dynamic equation is used, coupled with rapidly varied flow equations to represent discharges passing through breaches in dams or earth fills, in the form of internal boundary conditions. The dam break hydrograph to be routed may be specified as an upstream boundary condition or may be calculated by the model as a function of the breach and reservoir characteristics. Main results obtained are water profiles, hydrographs and peak times for the wave generated (Fread [5]).

The model SMPBRK (Simplified Dam Break) is a simplified version of NWS DAMBRK, also developed by NWS to meet the requirements of inundation caused by dam breaks, demanding less information and computational resources. Model user may obtain fast predictions related with time and velocity of flow, as well as peak discharges along the downstream reach (Wetmore and Fread [6]). Largely used by the NWS and many other representatives of the scientific community, DAMBRK and SMPBRK models were succeeded by FLDWAV model (Fread and Lewis [6]).

HEC-RAS, by its turn, is a one-dimensional hydrodynamic model developed by the United States Army Corp of Engineers (USACE). It is probably one of the most used models in the world, with a large set of different possibilities applications, encompassing flood propagation, water profile calculations, sediment transport simulation, and, since the year of 2003, dam break simulation (Hu and Walton [7]).

Zhou et al. [8], Gee and Brunner [9] and Moreda et al. [10] made comparisons between NWS FLDWAV and HEC-RAS. One of the main conclusions of these works is that FLDWAV is a more stable model that produces faster results. On the other side, HEC-RAS has better pre and post processing functions, with a better graphic output. Both programs produced similar results.

Considering another set of model approximation, the hydrodynamics quasi2D models apply the one-dimensional Saint-Venant equations to the main stream line flow, also considering the flood plains interactions conforming a twodimensional flow net, composed by one dimensional equations. In the simplest representation form, flood plains may be connected to the main channel flow by a set of storage reservoirs. Other times, in more complex representations, these 
models consider dynamic flood plains. In this second case, in which hydrodynamic equations are also written to the flood plains, lays MODCEL (Mascarenhas and Miguez [11]), which will be used in this paper and briefly detailed in the next topic.

The choice of the model is dependant on particular aspects of each case: dam characteristics, dimensions of the reservoir, type of valley, downstream occupation, extension of inundation area, set of available data, among others (Almeida [12]).

\subsection{Modcel}

MODCEL is a free model, developed at the Federal University of Rio de Janeiro with a simple academic interface, but designed to represent complex systems. The construction of MODCEL was based on the concept of flow cells (Zanobetti et al. [13]) where land surface is represented through a set of homogeneous compartments. The cells interact with each other composing a two-dimensional flow net connected by several different hydraulic laws. Each cell also performs a rainfall run-off transformation. The mesh of cells results in a hydrodynamic looped model, in a spatial representation that covers all the basin area and links surface flows, channel flows and, eventually, in urban areas, underground pipe flows. However, all the mathematical relations written are one-dimensional. The main flow relation is the Saint-Venant dynamic equation, written in the conservative form. Figure 1 shows a schematic representation of a basin portion, divided into cells, with some of the possible interactions among them, forming a dynamic two-dimensional flow net.

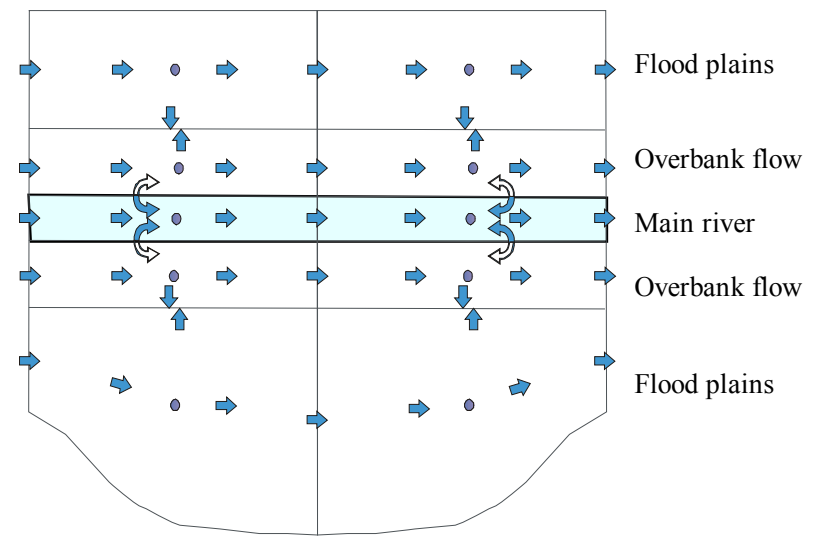

Figure 1: Hypothetical basin region modelled by cells, interacting and composing the spatial representation.

Several applications of this model, both in rural and urban areas, have been developed since 1991. The use of this model as a simulation tool for dam break wave propagation started in 2010 (Veról [14]), with the hypothetical dam break 
simulation of Funil dam, located at Paraíba do Sul River in Rio de Janeiro State, Brazil.

The wave front generated as a result of a dam break is abrupt, generally with a great magnitude. The occurrence of strong vertical accelerations in this region causes the hypothesis of hydrostatic pressure to fail. As a consequence, the classical Saint-Venant equations lose their validity. Some techniques, however, may be indicated to by-pass this problem and model the shock wave front. The Saint-Venant equations in their conservative form, because the benefit of the socalled weak solutions, allow to represent the dam break phenomenon. This aspect favours the use of MODCEL. Another possible approach is the use of a pseudo-viscosity, employed to introduce an artificial dissipation term for the area where the use of the classical equations disrupts. Mascarenhas [15] proposes to work with an increase in roughness using Manning coefficient as a way to introduce the equivalent effect of the pseudo-viscosity, generating the required dissipative effects. In MODCEL, the definition of a composite channel plus a detailed flood plain, which may be subdivided into different ground levels, allows the establishment of different Manning coefficients for each of the levels modelled. In this situation, the definition of increasing values for these coefficients, for each level created departing from the main channel, plays the role of introducing the dissipative effects. As the upper levels are reached, the greater the roughness coefficient is turned. Once the wave front has high depths and reach these upper levels of the flood plain, the dissipative effects for the "pseudo-viscosity" method may be obtained. Figure 2 illustrates this point.

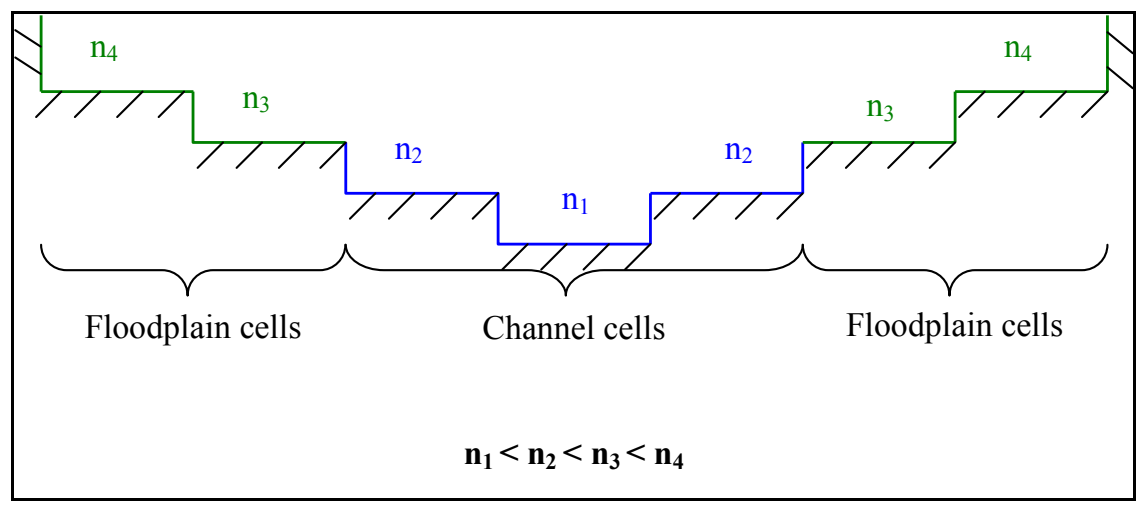

Figure 2: Manning Roughness coefficient variation, in order to introduce a local loss in the wave front region.

\section{Main elements for dam break flood maps}

The flood wave studies must be based on hypothesis that will indicate all areas that could be flooded, for the most severe combination of conditions. It should be considered, then, the possibility of mistakes on the design discharge, operation failures, or a dam break induced by an upstream structure failure (MIN [14]). 
Contingency plans or emergency action plans to face dam break accidents are very complex and must consider a set of integrated aspects, including monitoring the dam and the reservoir, measurement of hydrological and atmospheric data, establishment of a communication net and the conduction of educational campaigns, the definition of safe areas for valley population to shelter and safe roads and tracks to take, the strategic location of equipments and rescue vehicles, definition of procedures to be held by rescue teams, among others.

However, there is a set of technical information related to the dam break wave propagation phenomenon that is needed to start to produce these plans. This is the first step required to guide the planning process. Thus, mathematical modelling aid is essential in this case.

The results of a mathematical model for the dam break studies should be able to provide: the information of the water depths over the river main course and over de adjacent valley plains; the peak discharge value, its arrival time and the flow velocities associated with this discharge; and the times of permanence of the inundation at each affected area. These data, when combined with topographic maps and/or aerial images, are turned into the so-called flood maps and may give advice for flood response actions, providing enough information to enable the preparation of warning systems, contingency plans and the organisation of the urban settlements along the valley by the competent authority. In this work, as stated before, MODCEL will be used to fulfil these requirements.

The water depths are the basic response of the mathematical model, providing the flood maps with the inundation levels. Once MODCEL represents not only the main flow line, but also the entire valley, the resultant water levels are obtained by calculation throughout the basin, on the points pre-defined in flow net modelled by the user. There is no need of any kind of extrapolation from the main river course. Other important information obtained from the model results is the time of permanence of the valley inundation.

The discharges are also computed and some important aspects arise from this information. The peak discharge arrival time, or the time that the wave front takes to reach the communities and settlements along the river valley is essential to define the maximum time available for evacuating the population living there and that will be subjected to the wave attack. Other important information comes with the velocities calculation. This information gives an important indication of the destructive power of the flow. The velocity of flow may be combined with the water depth (by multiplying them both, for example) in order to establish a factor to be correlated to the capacity of the flow to drag people, objects, or even structures.

\section{Case study}

The dam of Funil Hydroelectric Power Plant, in the state of Rio de Janeiro, Brazil, which is upstream of some cities of great economic importance to the state, was chosen as a case study, 
Funil has the only double curvature arch dam in Brazil, as is shown in Figure 3. It was built in Paraíba do Sul River, on a site known as Salto do Funil, in Itatiaia city. Its operation began in 1969 and a year and a half later, the hydroelectric plant was already operating at its full capacity, with $216 \mathrm{MW}$.

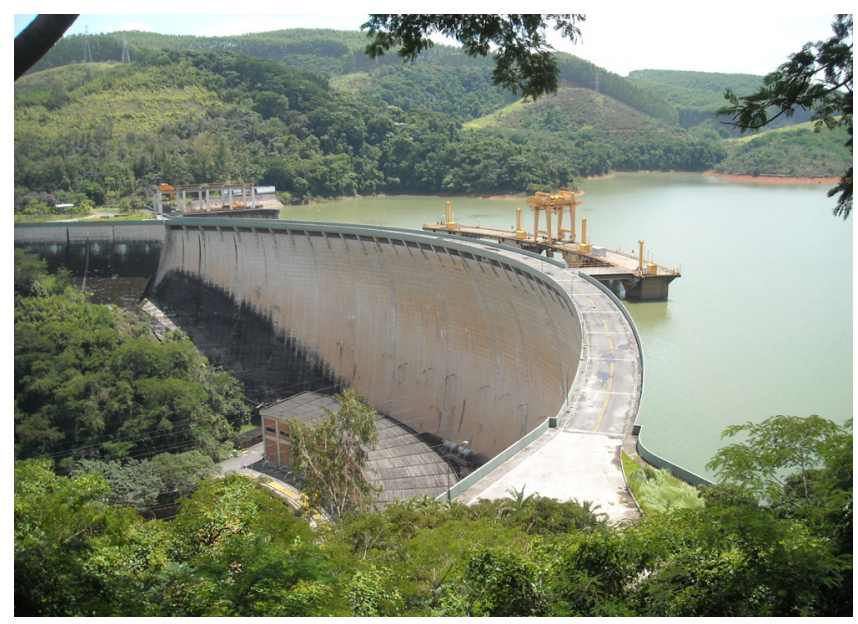

Figure 3: $\quad$ Funil dam and its reservoir.

Funil Dam has a total length of $385 \mathrm{~m}$, with an absolute elevation of $486.0 \mathrm{~m}$. Its total height is $85 \mathrm{~m}$. The water level control of the reservoir is accomplished by one service spillway on the right bank and two on the left, where the gates are installed. At the highest level $(466.5 \mathrm{~m})$, the reservoir has a $39.7 \mathrm{~km}^{2}$ of flooded area, with 888.3 million $\mathrm{m}^{3}$ of total accumulated volume.

This hydroelectric plant is considered of great importance because it is close to the major consuming centers, ensuring reliability of electric power supply to the states of Rio de Janeiro, São Paulo and Espírito Santo. Funil Dam also helped to reduce the frequency and the intensity of floods that occurred in the downstream cities.

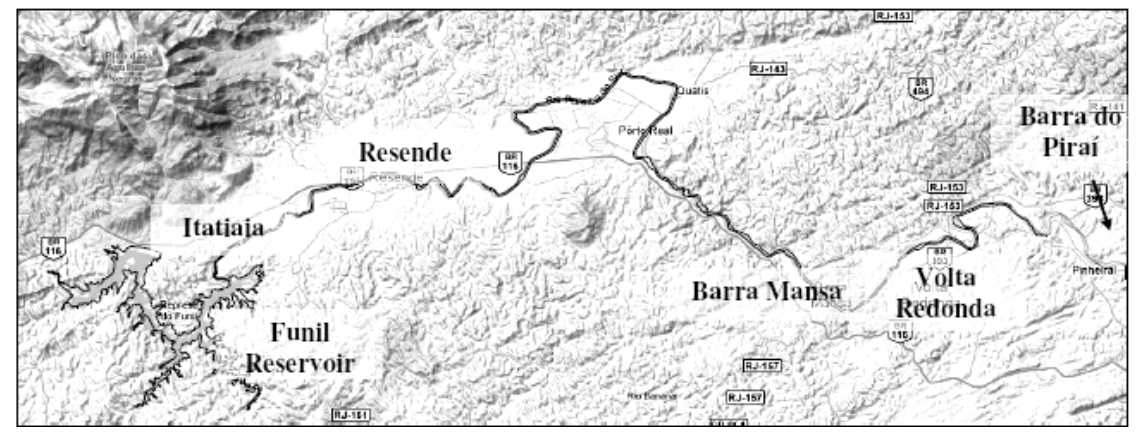

Figure 4: Paraíba do Sul River reach and the most important cities in the region. 
This study considered an extension of $107 \mathrm{~km}$ of Paraíba do Sul River, from the Funil Dam until the beginning of the urban area of Barra do Piraí city. Figure 4 shows a schematic map of the considered study reach, with the most important cities in the region.

Paraíba do Sul River is very sinuous in this region: sometimes running in a narrow valley, sometimes bordering vast plains. The first $60 \mathrm{~km}$ are of a wide floodplain, with great curves and smooth slopes on the main river course. The cities of Itatiaia and Resende, distant $5 \mathrm{~km}$ and $15 \mathrm{~km}$, respectively, from the Funil Dam, are in this first reach. The subsequently reach, with an extension of $15 \mathrm{~km}$, is characterized by a very narrow valley, free of occupation, and by Bananal River inflow, on the left bank. The last reach comprises the cities of Barra Mansa and Volta Redonda, which are $70 \mathrm{~km}$ and $80 \mathrm{~km}$ distant from the Funil dam, respectively. Both of them have dense urban areas on Paraíba do Sul River banks.

As MODCEL input data, it was necessary to define: the hydraulic and geometric characteristics of the flow sections in the modelled reaches of Paraíba do Sul River; the geometry of homogeneous storage areas, when appropriate; and the interactions among the various hydraulic structures or topographic features identified along the studied extension.

The longitudinal slope is not homogeneous and has very sharp variations after the cities of Barra Mansa and Volta Redonda. It was assumed that it varied from $0.000125 \mathrm{~m} / \mathrm{m}$ to $0.0005 \mathrm{~m} / \mathrm{m}$ along the considered reach.

The Manning coefficients were estimated from site observations. It was, then, considered 0.04 for the main channel and 0.10 for the floodplains. Higher values were adopted in the cells near the dam, to represent the shock region by means of the artificial pseudo-viscosity method.

In the simulation, the reservoir is represented by a cell that contains all its volume. The dam break phenomenon happens when a "wall of water" falls abruptly from the reservoir, once it was considered a total and instantaneous removal of the dam, because of its double curvature arch characteristics. It is possible, then, to observe the wave propagation, with the reduction of the reservoir volume. Both the positive and the negative waves can be seen by the model. Thus, MODCEL has the ability to calculate the dam break hydrograph which may be compared with analytical equation solutions found in the classical literature. In this situation, the upstream boundary condition considered was the water depth in the reservoir, before the hypothetical accident. In a hypothetical dam break wave propagation study, there aren't, of course, any measurements of the flow phenomena and the downstream boundary conditions are, therefore, unknown. An artifice that can be used is the virtual extended domain approach (Mascarenhas [17]), which assumes that the end of the real domain is located in an undisturbed zone and the new downstream boundary conditions are placed in a far extended domain and simply related to a practically constant value of a flow dependent variable in time. Then, the uncertainties introduced in the model results may become restricted simply to the virtual domain, while in the real length the results are approximately free of disturbances. Cunge et al. [18]) were the first researches to suggest the possibility of using this artifice. 
In this work it was used an artifice named virtual outfall, that complement the extended virtual domain idea. It consists on the creation of a cell of dimensions much larger and much deeper than the others in the model that will function as a kind of sink. So, at the edge of the extended modelled area all the downstream virtual cells spill to this sink, by a weir link.

MODCEL calculated the flood elevations, the peak flows and the corresponding time of occurrence. The results were transported to a topographic map, composing a flood map (Figure 5).

Figure 6 correlates the maximum water depth with the distance between the sections along the considered plains.

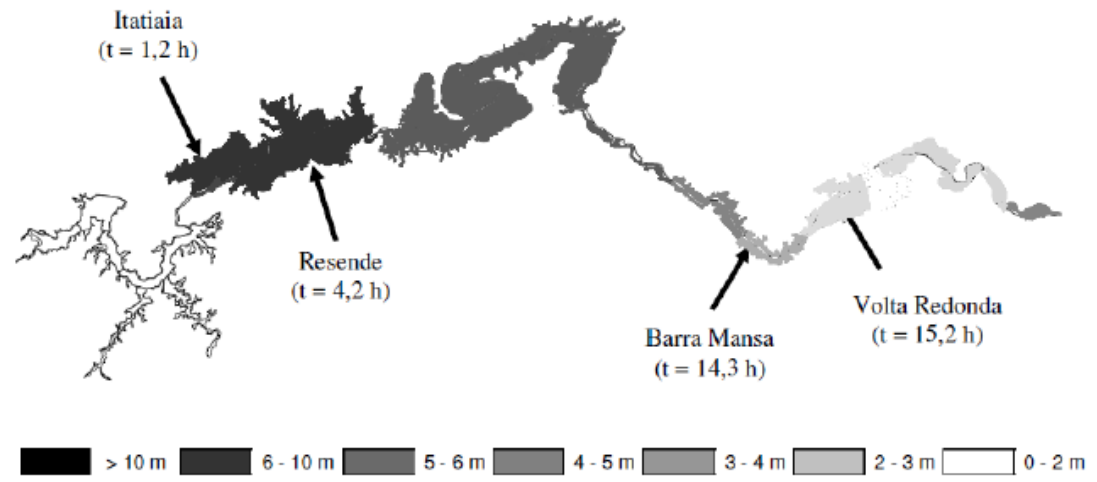

Figure 5: Flood map, with the time arrival of the dam break wave on some important cities.

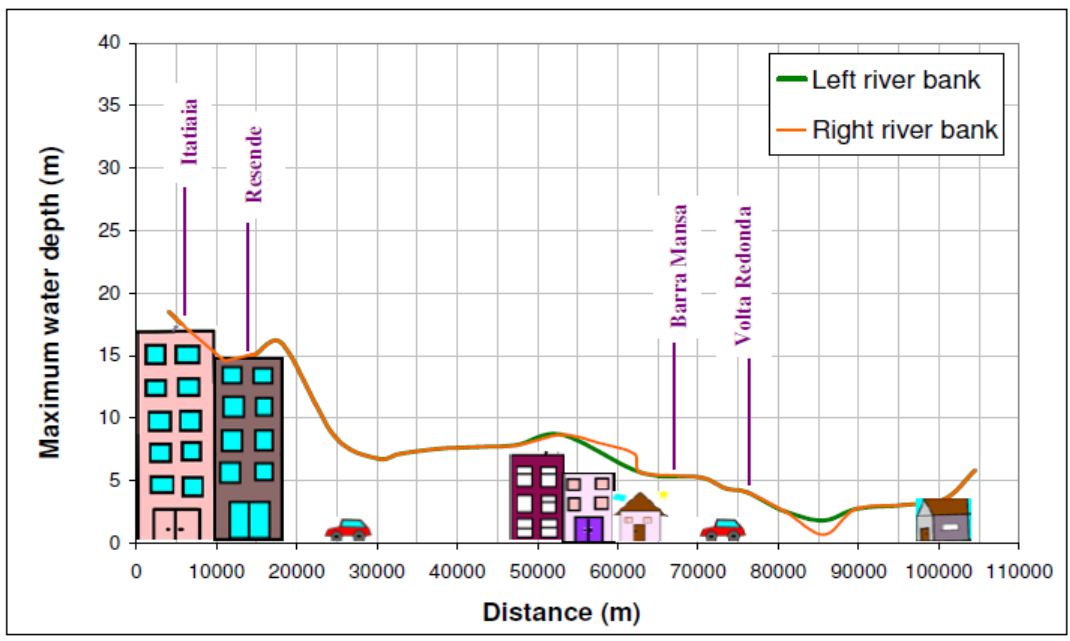

Figure 6: Maximum water depth along the considered reach. 
Throughout the studied reach, the maximum depth of the wave is large enough to cover homes and buildings. Itatiaia and Resende cities were the more severely affected regions, with water depths of $17 \mathrm{~m}$ and $15 \mathrm{~m}$, respectively. Barra Mansa reached the maximum of $5 \mathrm{~m}$, and Volta Redonda, $4 \mathrm{~m}$. Also, the time of the dam break wave arrival is important. In Itatiaia and Resende, the most critical cases, this time corresponds to $1.2 \mathrm{~h}$ and $4.2 \mathrm{~h}$, respectively, a short period of time to evacuate the city. In Barra Mansa and Volta Redonda, the wave takes more than $14 \mathrm{~h}$ to arrive. If the EAP works correctly, this period of time may be enough to evacuate the latter cities.

The velocity of flow was post-processed and the values were: $2.2 \mathrm{~m} / \mathrm{s}$ at Paraíba do Sul River near Itatiaia and $1.0 \mathrm{~m} / \mathrm{s}$ over Itatiaia flood plain; $3,6 \mathrm{~m} / \mathrm{s}$ at Paraíba do Sul River near Volta Redonda and $0.9 \mathrm{~m} / \mathrm{s}$ on the corresponding flood plains.

\section{Concluding remarks}

MODCEL was a very useful tool to simulate the phenomenon studied here. In dam break process, it is essential the dynamic simulation of the river flood plains, considering the high potential of the phenomenon to cause catastrophic flooding spreading for large areas. With MODCEL, it was possible to simulate the flow in a two-dimensional perspective, considering the floodplains in a hydrodynamic way.

The results of the simulation with MODCEL could provide: the information of the water depths over the river main course and over de adjacent valley plains; the peak discharge value, its arrival time and the flow velocities associated with this discharge; and the times of permanence of the inundation at each affected area. These data were combined with a topographic map and were turned into the so-called flood map.

The flood maps are useful to give advice for flood response actions, providing enough information to enable the preparation of warning systems, and the organisation of the urban settlements along the valley by the competent authority.

The results confirm how critical the dam break problem is and reinforce the importance of developing an EAP.

\section{References}

[1] McCully, P., When Things Fall Apart: The Technical Failures of Large Dams - In: Silenced Rivers: The Ecology and Politics of Large Dams. http://www.internationalrivers.org/files/srdamsafety.pdf

[2] Brazil. Federal Law 12,334, of September 20, 2010. Federal Official Gazette of Brazil, Brasília, DF, n. 181, 21 September. 2010. Section 1. (in Portuguese) 
[3] Fread, D.L., The development and testing of a dam break flood forecasting model. Proc. of Dam-Break Flood Modelling Workshop, U.S. Water Resources Council, Washington, D.C., pp. 164-197, 1977.

[4] Fread, D. L.; Lewis, J. M., NWS FLDWAV Model: theoretical description and user documentation. National Weather Service - Office of Hydrology (NOAA), Silver Springs, Maryland, 322 p., 1998.

[5] Fread, D. L., The NWS DAMBRK model: theoretical background / user documentation. Hydrologic Research Laboratory, Office of Hydrology, National Weather Service, NOAA, Silver Spring, Maryland, Revision 4, 1991.

[6] Wetmore, J.N., Fread, D.L., The NWS Simplified Dam-break flood forecasting model. Hydrologic Research Laboratory, Office of Hydrology, National Weather Service, NOAA, Silver Spring, Maryland, 1983.

[7] Hu, H.H., Walton, R., Advanced Guidance on Use of Steady HEC-RAS. In: World Environmental and Water Resources Congress 2008 Ahupua'a. May 12-16, 2008, Ahupua'a, Hawaii, USA. Edited by Raymond, W. \& Babcock, R., ASCE, 2008.

[8] Zhou, R.D., Judge, D.G.C., Donnely, R. Comparison of HEC-RAS with FLDWAV and DAMBRK models for dam break analysis. Canadian Dam. Association, 2005.

[9] Gee, D.M., Brunner, G.W., Dam Break Flood Routing using HEC-RAS and NWS-FLDWAV. EWRI/ASCE, 2005.

[10] Moreda, F., Gutierrez, A., Reed, S., Aschwanden, C., Transitioning NWS Operational Hydraulics Models from FLDWAV to HEC-RAS. In: World Environmental and Water Resources Congress 2009: Great Rivers. Kansas City, Missouri, USA, ASCE, 2009.

[11] Mascarenhas, F.C.B.; Miguez, M.G., Urban Flood Control through a Mathematical Cell Model. In: Water International, vol. 27, $\mathrm{N}^{\mathrm{o}} 2$, pp. 208218; Illinois, U.S.A, 2002.

[12] Almeida, A.B., Emergency and Risk Management. In: Dam Safety Course. (Chapter 7). Lisbon: National Institute of Water, 104p, 2001. (in Portuguese)

[13] Zanobetti, D.; Lorgeré, H.; Preissman, A.; Cunge, J.A., Mekong Delta Mathematical Program Construction. Journal of the Waterways and Harbours Division, ASCE, v.96, n.WW2, pp. 181-199, 1970.

[14] Veról, A.P., Simulation of Dam Break Wave Propagation Considering the Associated Flood Plain with the Use of a Pseudo Two-dimensional Model, MSc. Thesis, Federal University of Rio de Janeiro, Brazil, 2010. (in Portuguese)

[15] Mascarenhas, F. C. B., Mathematical Modelling of Waves Caused by Dam Failures, Ph.D. Thesis, Federal University of Rio de Janeiro, Brazil, 1990. (in Portuguese)

[16] Ministry for National Integration - MIN. Dam Safety Manual. Brasília, DF, 2002. (in Portuguese) 
[17] Mascarenhas, F.C.B., Dam-break wave routing using extended domain approach. In: Hydraulic Information Management. vol 52, pp. 211-221. WIT Press, Ashurst Lodge, Southampton, UK. Edited by CA Brebbia and WR Blain, 2002.

[18] Cunge, J.A.; Holly Jr., F.M.; Verwey, A., Practical Aspects of Computational River Hydraulics. Pitman Advanced Publishing Program, England, 1980. 